\title{
IMPACTOS DA SUSTENTABILIDADE E DA NOÇÃO DE VALOR COMPARTILHADO NO GOVERNO DA EMPRESA
}

Vinicius Figueiredo Chaves

Doutorando em Direito pela UERJ, na linha de pesquisa Empresa e Atividades Econômicas. Mestre em Direito Público e Evolução Social pela UNESA. Membro do grupo de pesquisas CNPq Empresa e Atividades Econômicas.Pesquisa realizada no âmbito do projeto Empresa, Eficiência e Justiça, financiado pela UNESA na forma do Edital Pesquisa e Extensão 2015, modalidade Pesquisa-Produtividade. E-mail: viniciuschaves@gmail.com

\section{Leonardo da Silva Sant'Anna}

Doutor em Saúde Pública pela FIOCRUZ. Professor do Programa de Pós-graduação em Direito da UERJ, na linha de pesquisa empresa e atividades econômicas. Professor Adjunto de Direito Comercial da UERJ. Membro do grupo de pesquisas.

\section{Resumo}

O objetivo deste artigo é demonstrar os impactos da sustentabilidade e da noção de valor compartilhado no governo da empresa. Parte-se da noção de sustentabilidade como elemento estruturante do Estado Constitucional, um novo paradigma do direito na pósmodernidade, designado por três pilares em torno dos quais a empresa deve se engajar, com repercussão no redimensionamento de sua atuação para criaçáo de valor compartilhado a todo um conjunto de partes interessadas. Em seguida, examinam-se conceitos e abordagens predominantes relacionadas com a questáo do governo da empresa, do ponto de vista doutrinário e também no âmbito de organismos internacionais como a OCDE e a ONU. Percebeu-se que a visão tradicional da doutrina sobre o tema do governo da empresa se encontra associada à ideia de soluçáo de conflitos de agência entre titularidade e gestão ou entre majoritários e minoritários. A OCDE e a ONU já consagram algumas diretrizes de princípios de governo de empresa associados às ideias de sustentabilidade e criação de valor compartilhado, mas tais mecanismos são de adesão voluntária, constituindo soft law, direito não prescritivo. Conclui-se que a visão tradicional da doutrina é insuficiente para uma efetiva adequação do governo da empresa à sustentabilidade e também para a harmonização dos múltiplos interesses, privados e públicos, que gravitam em torno deste fenômeno.

\section{Palavras-chave}

Sustentabilidade; Valor compartilhado; Empresa; Governo da empresa. 


\section{Abstract}

The purpose of this paper is to demonstrate the impacts of sustainability and the concept of shared value in the corporate governance. It starts with the notion of sustainability as a structural element of the constitutional state, a new paradigm of law in post-modernity, based on three pillars on which the company must engage, with repercussions on the resizing of its activities to creating shared value to a range of stakeholders. Then, we examine concepts and prevailing approaches related to the issue of the corporate governance, considering the doctrinal point of view and also within international organizations as OCDE and ONU. It was noticed that the doctrine traditional view of the corporate governance subject the enterprise is associated with the idea of offering solutions to agency conflicts between ownership and management or between majority and minority. OCDE and ONU already provided some guidelines of enterprise principles of governance associated with sustainability and creating shared value ideas, but this kind of mechanisms are voluntary, being soft law, not prescriptive law. We conclude that the traditional view of the doctrine is insufficient for effective fitness of corporate governance to sustainability and also to harmonize multiple interests, public and private, that gravitate around this phenomenon.

\section{Key words}

Sustainability; Shared value; Enterprise; Corporate governance.

\section{Introdução}

$\mathrm{Na}$ quadra final do século XX, a sustentabilidade é alçada ao patamar de elemento estruturante do Estado Constitucional, um novo paradigma do direito na pós modernida$\mathrm{de}^{1}$. Como tal, passa a ser o pano de fundo de debates que repercutem na compreensão da realidade social, econômica e jurídica. Não mais restrita ao aspecto ambiental ou ecológico, essa discussão atualmente engloba também outras perspectivas como a econômica e a social. Consequentemente, impóe desafios à governança dos atores públicos e privados, dos quais se passou a demandar maior compromisso com a responsabilidade socioambiental.

Foco central destas discussóes parece ser a empresa ${ }^{2}$. Tem-se ventilado que, aplicadas as novas perspectivas e dimensóes em torno da questão da sustentabilidade, esta encontra-se

1 Conforme anotam CRUZ e BODNAR (2011, p. 78), a expressão paradigma não possui um conceito único, vindo a sofrer no campo das ciências sociais influências ideológicas e socioculturais. Para fins do presente trabalho, será adotado o conceito de paradigma formulado pelos próprios autores, qual seja: “o critério de racionalidade epistemológica reflexiva que predomina, informa, orienta e direciona a resolução dos problemas, desafios, conflitos e o próprio funcionamento da sociedade. Trata-se de um referente a ser seguido e que ilumina a produção e aplicação do direito".

2 Não se utilizará a noção de empresa adotada pelo Código Civil de 2002 (empresa = atividade econômica organizada), considerada restrita diante de sua visão poliédrica. Entende-se a empresa como instituiçáo 
diante da necessidade de ampliação de responsabilidades sociais e redefinição de papeis e missão na sociedade, que impóem uma visão mais ampla aos seus relacionamentos, no sentido da incorporação de consideraçóes de ordem social e ambiental aos negócios e operaçóes desenvolvidos. Neste sentido, discute-se se o tema da governança corporativa ${ }^{3}$ engloba a necessidade, ou não, de uma adequação às ideias em torno da sustentabilidade e também da noção de criação de valor compartilhado a um conjunto de partes interessadas, para além dos titulares da atividade econômica.

Frente a este problema específico de pesquisa, o presente trabalho assume o objetivo de investigar os eventuais impactos da sustentabilidade e da noção de valor compartilhado na temática do governo da empresa. Por outro lado, questóes como a existência de conflitos internos de agência, falhas na apresentação de informações financeiras ao mercado, diminuta participação de conselheiros independentes, falta de representação dos empregados nos conselhos de administração, não incor poração da política de divulgação de informaçóes sobre sustentabilidade etc., demandam que o debate sobre a necessidade de adequação do agir empresarial incorpore também reflexóes acerca dos meios regulatórios mais adequados ao tratamento de determinadas matérias. Em última análise, a opção por um direito prescritivo, cogente (hard law), ou um direito mais brando, flexível (soft law).

A pesquisa se justifica em função do destacado papel que a empresa exerce na sociedade contemporânea, com suas decisões impactando a vida das pessoas, das famílias, dos ecossistemas e de países inteiros. A forma como as empresas são dirigidas tem constituído objeto de debates interdisciplinares, em diversos países do mundo, em que proliferam os chamados códigos de conduta e boas práticas de governança.

A fim de analisar estas questóes, a metodologia utilizada foi a pesquisa documentalbibliográfica, por meio de análise de documentos legais, livros e artigos científicos assinados por autores nacionais e internacionais (SEVERINO, 2007), assim como de consultas a sítios eletrônicos de organismos internacionais como a Organização para a Cooperação e o Desenvolvimento Econômico (OCDE) e a Organização das Naçôes Unidas (ONU).

econômico-social, e não como mera expressão de atividade econômica. Para aprofundamento sobre o tema da natureza jurídica da empresa, interessante consultar a obra de LEMOS JÚNIOR (2009), cujo capítulo III expóe algumas das teorias sobre o assunto, como as seguintes visóes: i) A empresa como instituição; ii) Teoria de Hauriou; iii) Teoria de Santi Romano; e iv) A empresa como fattispecie (atividade).

3 É comum encontrar na doutrina algumas propostas de expressóes alternativas ao termo governança corporativa, tais como governo de empresas, governo societário das empresas e governaçâo das sociedades comerciais. A questão será detalhada de maneira mais aprofundada no ítem 3 do presente trabalho. Para fins desta investigação, será privilegiada a expressão governo da empresa, que engloba a noção de atividade, mas a ela não se restringe. Da mesma forma, encampa a noção de sociedade, mas a ela não se encontra adstrita (na medida em que há empresas não societárias). Termos como governo societário das empresas e governação das sociedades comerciais, considerada, por exemplo, a realidade brasileira, não englobariam formas de organização jurídicas como a EIRELI (entende-se, diferente de parte respeitável da doutrina brasileira, que a empresa individual de responsabilidade limitada não é uma sociedade, embora seja pessoa jurídica e, como tal, apta a exercer direitos e contrair obrigaçóes independentemente da pessoa de seu titular). 


\section{A Sustentabilidade: Do Ecodesenvolvimento a uma Perspectiva Ampliada, com Impacto na Redefinição dos Papeis dos Atores Sociais}

A ideia de sustentabilidade "ganha corpo e expressão política na adjetivação do termo desenvolvimento, fruto da percepção sobre uma crise ambiental global” (NASCIMENTO, 2012, p. 52). As primeiras referências ao desenvolvimento surgem na década de cinquenta do século passado, a partir da percepção, pela humanidade, da existência de um risco comum decorrente de um processo de degradação ambiental (CHAVES; FLORES, 2015, p. 3). A partir de entáo, ambos os assuntos passam a ser discutidos no âmbito político e também acadêmico.

Naquele tempo, a noçáo de sustentabilidade se encontrava ancorada somente ao indicador meio ambiente, o chamado ecodesenvolvimento ${ }^{4}$. À época, tal perspectiva, hoje considerada limitada, justificava-se diante dos impactos causados pelos estudos e conlusóes do chamado Clube de Roma - no sentido do reconhecimento da necessidade de imposição de limites ao crescimento em função da já constatada degradação ambiental e escassez dos recursos ambientais,$-{ }^{5}$ e especialmente em face da preocupação com a realização de inúmeros testes nucleares entre os anos de 1945 e 1962, que culminaram em chuvas radioativas sobre os países nórdicos e acabaram por levar a Suécia, em 1968, a propor às Naçóes Unidas a realização de uma conferência a nível mundial, para discussóes com vistas à redução da emissão dos elementos então compreendidos como responsáveis pelas chuvas ácidas (NASCIMENTO, 2012, p. 53).

Este encontro veio a ocorrer em 1972, em Estocolmo, a I Conferência Mundial das Naçóes Unidas sobre Meio Ambiente Humano (CNUMAH). O documento final da Conferência, a Declaração de Estocolmo, em seus Princípios, preceituava ao homem a "[...] solene obrigação de proteger e melhorar o meio ambiente para as geraçóes presentes e futuras", reconhecendo simultaneamente que "nos países em desenvolvimento, a maioria dos problemas ambientais estão motivados pelo subdesenvolvimento" e que, neste sentido, "milhões de pessoas seguem vivendo muito abaixo dos níveis mínimos necessários para uma existência humana digna [...]". Portanto, prescrevia que os "países em desenvolvimento devem dirigir seus esforços para o desenvolvimento, tendo presente suas prioridades e a necessidade de salvaguardar e melhorar o meio ambiente".

Com o tempo, a compreensão de sustentabilidade ancorada somente no indicador meio ambiente foi deslocada também para outros eixos mais abrangentes. Tal como

4 Sobre o ecodesenvolvimento, oportuno destacar a lição de MONTIBELLER FILHO (1993, p. 133): “O econdesenvolvimento pressupōe, entáo, uma solidariedade sincrônica com a geraçáo atual, na medida em que desloca a lógica da produçâo para a ótica das necessidades fundamentais da maioria da população; e uma solidariedade diacrônica, expressa na economia de recursos naturais e na perspectiva ecológica para garantir às geraçóes futuras as possibilidades de desenvolvimento”.

5 Os trabalhos e conclusôes do Clube de Roma ensejaram a publicação da obra Limits to growth. MEADOWS, D. H. et al. The limits to growth. New York: Universe Books, 1972. 
destaca FEITOSA (2009, p. 33-34), a sustentabilidade não se baseia mais somente num sentido restrito ou ecológico, sendo que "o marco desta compreensão é o relatório da Comissão Mundial da ONU sobre o Meio Ambiente e Desenvolvimento (UNCED), de 1987, intitulado 'Our Common Future' . Já naquele momento, a ampliação de perspectivas em torno do conceito de desenvolvimento ${ }^{7}$ podia ser percebida mediante a vinculação do termo à ideia de satisfação de necessidades presentes sem comprometimento da garantia das mesmas possibilidades às geraçóes futuras, indicando também a perspectiva de um olhar intergeracional, aspecto da solidariedade que denota uma dimensão ética.

Após o Relatório Brundtland, o conceito de desenvolvimento sustentável foi posto no centro dos debates internacionais especialmente por ocasião da chamada "Cúpula da Terra”, a Conferência das Naçóes Unidas sobre Meio Ambiente e Desenvolvimento. O encontro aconteceu no Rio de Janeiro, em 1992, e reuniu um total de 178 naçóes. Ao seu final, foi editado um plano de ação global conhecido como Agenda 21, que traçava um programa comum em torno de alguns alicerces do desenvolvimento sustentável, "para atender equitativamente as necessidades, em termos de desenvolvimento e de ambiente, das geraçôes atuais e futuras".

Outro acontecimento marcante a nível mundial foi a Cúpula Mundial do Desenvolvimento Sustentável, realizada em 2002, em Johanesburgo, onde restaram reafirmados compromissos assumidos com o desenvolvimento sustentável, inclusive a construção de uma sociedade global, humanitária, equitativa e solidária, através da ratificação de metas anteriormente assumidas para a proteção do meio ambiente e das metas estabelecidas na Agenda 21 (MARIANO, 2012, p. 29). Todos esses marcos históricos foram importantes para que a ideia de sustentabilidade passasse a ser composta por três indicadores: atividade econômica, meio ambiente e bem estar da sociedade ${ }^{8}$.

A partir dessa concepção expandida, a sustentabilidade passa a ser apontada como um "novo paradigma secular, do gênero daqueles que se sucederam na gênese e

6 Também conhecido como 'Relatório Brundtland', em homenagem à entāo primeira ministra da Noruega, Gro Harlem Brundtland, responsável por presidir a Comissão, instalada em 1983.

7 Embora não sejam poucos os autores que reconhecem a sustentabilidade e o desenvolvimento sustentável como sinônimos, para LACERDA, ROSA e FERRER (2014, p. 1204) sustentabilidade e desenvolvimento sustentável são termos que não se confundem, embora a sustentabilidade venha ganhando espaço crescente nos discursos sobre o desenvolvimento. Segundo os autores (p. 1213-1214), somente ao assumir e substituir o paradigma até então predominante, do crescimento, o adjetio sustentável incorpora o objetivo de crescimento e pode passar a ser tratado como desenvolvimento sustentável.

8 Há autores que referenciam outras dimensôes, tal como SACHS (1993), que aponta cinco: i) Sustentabilidade Social; ii) Sustentabilidade Econômica; iii) Sustentabilidade Ecológica; iv) Sustentabilidade Espacial; e iv) Sustentabilidade Cultural. Já Gabriel Real Ferrer, Maikon Cristiano Glasenapp e Paulo Márcio Cruz (2014, p. 1456), descrevem que a sustentabilidade pode ser entendida em dois sentidos restrito e amplo -, sendo que neste último apresentaria seis dimensôes: i) Ecológica; ii) Econômica; iii) Social; iv) Cultural; v) política-jurídica; e vi) Tecnológica. Neste artigo seguiremos trabalhando com o conceito tridimensional, devido à crença de que cada um dos três elementos pode englobar outros, sem necessidade de ampliação desta configuração. 
desenvolvimento do constitucionalismo", como foram o humanismo, a questão social e a democracia social, respectivamente nos séculos XVIII, XIX, XX (CANOTILHO, 2010 , p. 8). Este novo paradigma do direito - indutor de pautas axiológicas em diversos níveis- ${ }^{9}$, dotado de múltiplas faces ${ }^{10}$, impóe complexos desafios à governança pública e privada, com reflexos diretos na necessidade de redefinição de papeis dos atores sociais diante de um novo conjunto mais amplo de perspectivas e expectativas.

\section{Empresa, Stakeholders e Valor Compartilhado}

"Lucro e respeito à lei contam, mas são apenas parte da história".

Ricardo Abramovay

Diante desta concepção expandida em torno da noção de sustentabilidade, tem sido ventilado que o mundo precisa de uma nova economia, uma vez que a maneira atual de organização de recursos, embora tenha favorecido uma crescente prosperidade material, supostamente não atende ao objetivo maior de contribuir para a ampliação de liberdades substativas dos seres humanos como um todo, assim como põe em cheque - destruição ou séria ameaça - nada menos do que 16 dos 24 serviços prestados pelos ecossistemas (ABRAMOVAY, 2012, p. 15). Um dos grandes desafios dessa reflexão "é que formular objetivos para o sistema econômico que não dependam fundamentalmente de sua expansão permanente significa também formular metas para as firmas que alterem o sentido da ação empresarial e as medidas de sua eficiência” (ABRAMOVAY, 2012, p. 17) . Em outras palavras, a emergência desta nova economia traz à reboque a igualmente necessária redefinição dos papeis dos agentes sociais, dentre os quais as empresas, no sentido da adoção dos chamados comportamentos sustentáveis, orientados para a harmonização entre aspectos econômicos, sociais e ambientais, e não apenas pelo escopo de lucro no curto prazo. Neste sentido, opera-se a inclusão dos atores privados na busca do desenvolvimento sustentável.

De fato, dada a sua presença - muitas vezes global -, poder econômico e mobilidade, incluir as empresas enquanto agentes promotores do desenvolvimento sustentável constitui caminho natural e inexorável (PINHEIRO, 2012, p. 25). No caso específico da empresa, trata-se de uma visão mais ampla dos relacionamentos empresariais, no sentido da incorporação de consideraçóes de ordem social e ambiental aos negócios e operações

9 No mesmo artigo referenciado na nota acima, FERRER, GLASENAPP e CRUZ (2014) apontam corretamente a sustentabilidade como um novo paradigma para o direito.

10 A sustentabilidade, fenômeno de muitas faces, foi assim acertadamente tratada na obra "A Sustentabilidade Ambiental em suas Múltiplas Faces” (FLORES, 2012). Algumas das múltiplas faces da sustentabilidade foram discutidas em inúmeros capítulos que tangenciam a governança de atores públicos e privados. 
desenvolvidos, com a ética ocupando posição central nas decisôes e estratégias. Os referidos alicerces indicam que a missão da empresa deve aliar engajamento ecológico, econômico e social, que considere náo apenas o sentido de sua existência, sua razáo de ser e sua legitimidade, mas também sua finalidade (LAVILLE, 2009, p. 160).

A empresa desempenha um papel central na sociedade, com suas decisóes impactando a vida das pessoas, das famílias, dos ecossistemas e de países inteiros (MACKEY; SISODIA, p. 283). É natural, portanto, que lhe seja dirigida um conjunto de expectativas, em função de sua capacidade de contribuir positiva ou negativamente para o desenvolvimento sustentável. Embora atualmente venha se consolidando a ideia de que tais expectativas não podem ser ignoradas, por muito tempo, o foco excessivo na maximização de resultados econômicos de curto prazo aos shareholders (sócios / acionistas) acabou por gerar um contexto de crise no relacionamento das empresas com a sociedade. Esta concepção, segundo relata TEIXEIRA (2010, p. 226), acorrentou o referido instituto à crise epistemológica do modelo de desenvolvimento utilizado no século XX, então pautado em crescimento econômico apenas quantitativo e acumulativo. Segundo a autora, o modelo em questão decorreu da dissociação entre a humanidade (sociedade), suas organizaçóes e o meio ambiente e acarretou reflexos no desalinhamento entre os interesses da sociedade e os de suas instituiçóes, especialmente o Estado e as empresas (estas focadas somente em resultados econômicos de curto prazo).

Diante daquele cenário, passou-se a sustentar a necessidade de harmonização dos interesses particulares com compromissos sociais, em face da consolidação da ideia de que as empresas não desenvolvem suas atividades num vácuo social, mas sim diante de questôes fundamentais como expectativas, valores, matrizes sociais e processos comunicacionais mais amplos com a sociedade. Nesta esteira, tal como descrevem SEN e KLIKSBERG (2010, p. 362-364), as ideias acerca do papel a ser desempenhado pelas empresas privadas na sociedade contemporânea se modificaram aceleradamente nos últimos anos, passando de uma visão que defendia a geração de lucro para seus proprietários - somente a quem deveriam prestar contas - como a sua única responsabilidade, a uma perspectiva que vai muito além, promovendo uma ruptura paradigmática em relação às concepçóes anteriores, no sentido de considerá-las com alta responsabilidade social ${ }^{11}$. Neste sentido, fala-se na necessidade de ampliar responsabilidades sociais e redefinir o papel e missão das empresas na sociedade (ARNOLDI; MICHELAN, 2000, p. 159).

11 Importante ressaltar que a questão da responsabilidade social se encontra relacionada à ideia de "integração voluntária de preocupaçôes sociais e ambientais por parte das empresas nas suas operaçóes e na sua interação com a comunidade" (TOMASEVICIUS FILHO, 2003, p. 46), diferenciando-se da noção de função social. 
$\mathrm{O}$ advento do conceito de stakeholders ${ }^{12}$ foi fundamental para o surgimento de uma nova visão para a atuação das empresas. Em tradução não literal, o termo tem sido usado para definir um conjunto de "partes interessadas" direta ou indiretamente afetadas pelas atividades econômicas exercidas pela empresa, tais como: empregados, consumidores, comunidade, meio ambiente, entre outros. Tal visão é pautada no entendimento de que as empresas devem criar o maior valor possível para todas as "partes interessadas".

Conforme ensina FREEMAN (2010, p. 24-26), contesta-se a visão tradicional da firma ${ }^{13}$, baseada na premissa de que a maximização de lucros para sócios e acionistas seria a sua única finalidade, assumindo-se a noção de que as empresas devem criar o maior valor possível para todo um conjunto mais ampliado de partes interessadas, náo somente para os titulares da atividade econômica. Segundo o autor,

In the traditional view of the firm, the shareholder view, the shareholders or stockholders are the owners of the company, and the firm has a binding financial obligation to put their needs first, to increase value for them. However, stakeholder theory argues that there are other parties involved, including governmental bodies, political groups, trade associations, trade unions, communities, financers, suppliers, employees, and customers. Sometimes even competitors are counted as stakeholders - their status being derived from their capacity to affect the firm and its other stakeholders.

A ampliação e desenvolvimento de estudos sobre a teoria dos stakeholders fez com que se passasse a constestar a doutrina de criação de valor somente para os shareholders ou stockholders (sócios/acionistas) - que vê a empresa como um instrumento cujo único propósito é a perseguição de resultados econômicos, movida por interesses exclusivos de agentes racionais que maximizam utilidades -, que assim passa a ser considerada como um mito (STOUT, 2012).

Floresce, a partir daí, a noção de criação de valor compartilhado (PORTER; KRAMER, 2011): a ação das empresas não pode ser voltada somente para o desempenho econômico-financeiro, especialmente o de curto prazo. Deve contemplar também os direitos de todas as partes interessadas, uma redefinição de suas finalidades que permita uma maior contribuição para a realização do desenvolvimento e para a sustentabilidade. A empresa, desse modo, trata-se de "mucho mas que una entidad simplesmente económica,

12 O conceito de stakeholders foi abordado no artigo Stockholders and Stakeholders: A New Perspective on Corporate Governance, publicado em 1983 pela California Management Review. Segundo os autores, o próprio R. Edward Freeman, em coautoria com David L. Reed, o termo fora veiculado antes, em 1963, em memorando interno da Standford Research Institute, como referência a "aqueles grupos sem cujo apoio a organização não existiria”.

13 Firma é um termo utilizado frequentemente pelas teorias econômicas como sinônimo de empresa. Deve-se resssaltar que, no Brasil, no plano jurídico, firma consiste numa das modalidades de nome empresarial. 
transformada en una instituición con gran peso a nivel social' (ANDRÉS; PIMENTEL, 2005, p. 37).

\section{Empresa e Governança: As Visões Tradicionais da Temática do Governo da Empresa}

Atualmente, a forma como as empresas são dirigidas tem constituído objeto de debates nos mais variados quadrantes, tal como na administração, na economia e no direito ${ }^{14}$. De fato, as práticas de governança geram uma gama de opinióes de diversos grupos de partes interessadas, investidores, instituiçóes de mercado, e também de autoridades reguladoras e legisladores (MAHONEY, 2007, p. 191).

De uma forma geral, o tema é desigando por intermédio da expressão governança corporativa, que consiste numa tradução literal do termo corporate governance. Embora seja corrente a utilização do referido anglicismo, muitas críticas lhe são formuladas, especialmente nos países de língua portuguesa, em que normalmente se lhe objeta o uso ${ }^{15}$. Neste sentido, é também comum encontrar na doutrina algumas propostas de expressóes alternativas ao termo, tais como as formuladas por WALD (2002, p. 53) - que se refere a governo de empresas -, SILVA (2009, p. 40) - governo societário das empresas -, e ABREU (2010) - governaçâo das sociedades comerciais.

Para além das controvérsias em torno da eleição de expressôes mais ou menos adequadas, a questão mais importante parece o entendimento sobre o que venha a ser governança, assim como os seus propósitos. Desde o clássico trabalho de BERLE e MEANS (1932), considerado seminal nas discussóes sobre o tema, a governança tem sido apresentada primordialmente como um conjunto de medidas voltadas à solução de problemas de agência entre titularidade e gestão, ou também entre titulares majoritários e minoritários do capital social.

A manifestação mais expressiva deste ponto de vista sobre a existência de conflitos entre titularidade e gestão ${ }^{16}$ se desenvolveu especialmente a partir da publicação da obra

14 Tradicionalmente, as discussóes sobre o tema da governança têm abarcado exclusivamente o tipo societário conhecido como sociedade anônima. Não obstante o reconhecimento da grande relevância da sociedade anônima, o presente trabalho buscará enfrentar o tema do governo da empresa de uma maneira mais geral, considerando, mas náo se restringindo, ao tipo societário em questáo.

15 WALD (2002, p. 54) destaca que, para além do respeito à língua portuguesa, deve também ser observado que o termo governança corporativa pode levar a uma associaçáo equivocada de ideias. Segundo o autor, as noçóes de empresa e de sociedade anônima náo comportam as características das corporaçóes (estas últimas ligadas a categorias profissionais), e o uso do termo corporativo(a) aproxima da noção da prevalência de interesses de um grupo ou de uma classe, devendo ser rechaçado.

16 A discussão, inicialmente travada em contextos de países em que há grande dispersão acionária, alastrase em seguida também para outras realidades onde, em sua maioria, uma pessoa ou pequenos grupos de 
de JENSEN e MECKLING (1976, p. 307-308), na qual os autores - tendo como objeto de análise a sociedade anônima no contexto americano, caracterizado pelo fenômeno da dispersão acionária - definem a relação de agência como uma espécie de contrato em que uma ou mais pessoas, na condiçáo de principais, designam poderes de decisão para o (s) agente (s), ou seja, uma ou mais pessoas encarregadas de executar serviços de gestáo em benefício dos principais. No bojo desta relação, diante da dificuldade de alinhamento de interesses nem sempre coincidentes, surge a necessidade de monitoramento dos agentes pelos principais, gerando assim uma série de custos - os chamados custos de agência -, influenciados por diversos fatores.

Segundo WALD (2002, p. 55), a noção de governo da empresa se encontra atrelada ao estabelecimento do Estado de Direito na empresa e se refere à organização e à dinâmica dos poderes, passando também pela adequada definição dos órgáos sociais e das respectivas competências, bem como pela questão dos direitos e deveres dos vários acionistas. Para o autor, o governo se encontra associado à ideia de institucionalização da empresa, que se opera pela regulamentaçáo de sua estrutura administrativa, corporificada no conjunto de medidas que assegura o funcionamento eficiente, rentável e equitativo das empresas. Neste sentido, deve assegurar a prevalência do chamado interesse social sobre eventuais interesses particulares dos acionistas, sejam eles controladores ou não.

Nas palavras de LOBO (2006, p. 141), governança corporativa consiste no conjunto de normas, consuetudinárias e escritas, tanto de cunho jurídico quanto ético, que regulam os deveres de cuidado, diligência, lealdade, informação e não intervir em qualquer operaçáo em que tiver interesse conflitante com o da empresa. Regulam, igualmente, o exercício das funções, atribuiçôes e poderes dos membros dos órgãos da sociedade como o conselho de administração, a diretoria executiva e o conselho fiscal, assim como dos auditores externos. Por fim, destaca que tal regulaçáo se estende ao relacionamento destes membros entre si e com a própria sociedade, seus acionistas e o mercado em geral.

Por sua vez, SILVA (2013, p. 63) destaca que o governo das sociedades propóe evitar os problemas problemas de agência que surgem da separação da propriedade e do controle e também aqueles relativamente aos accionistas maioritários e minoritários. Descreve que há também a finalidade de melhorar a confiança dos investidores, medida necessária para o adequado funcionamento de uma economia de mercado, assim como a própria eficiência econômica e o crescimento.

pessoas detêm a titularidade da maior parte das açóes de uma sociedade anônima, o que lhes garante a condição de acionistas majoritários, em convívio com os titulares de participaçóes menos expressivas no capital, os chamados acionistas minoritários. 
Vale também apontar a noção de governança empregada por instituiçôes de mercado. Como exemplo, destaca-se o Instituto Brasileiro de Governança Corporativa - IBGC ${ }^{17}$ (2009, p. 19), que atrela o governo da empresa à ideia de sistema pelo qual as organizaçóes são dirigidas, monitoradas e incentivadas, e que envolve um conjunto de relacionamentos internos entre proprietários, conselho de administração, diretoria e órgãos de controle. Prega-se o alinhamento de interesses à nível interno e a conversão de princípios em recomendaçóes objetivas, com a finalidade de preservar e otimizar o valor da organização, o que facilitaria seu acesso ao capital e contribuiria para a sua longevidade.

Percebe-se, em todas as definiçóes, uma preocupação interna corporis relacionada à ideia da existência de conflitos de interesses no âmago da empresa, entre os titulares de participação majoritária e minoritária e os membros de órgãos internos. Em que pese a necessidade de consolidação de um sistema capaz de acomodar atividade econômica, meio ambiente e bem estar da sociedade, não se vislumbra a questão da incorporação da sustentabilidade e da noção de criação de valor compartilhado.

Nas visóes tradicionais sobre o tema do governo da empresa, os stakeholders - e, consequentemente, a ideia de um feixe de interesses privados e públicos, cuja harmonização é necessária -, normalmente são postos à margem, ou mesmo encontram-se inseridos ao debate, mas em análises de cunho meramente estratégico, que englobam apenas as conexôes da governança para com o desempenho financeiro (ATKINSON; WATHERHOUSE, 1997).

\section{Princípios da OCDE sobre Governo das Sociedades}

Os Princípios da Organização para a Cooperação e o Desenvolvimento Econômico - OCDE $^{18}$ (2004, p. 17-25) sobre governo de sociedades ${ }^{19}$ visam constituir ferramenta de auxílio no sentido da avaliação e melhora do enquadramento legislativo, institucional e regulamentar no âmbito da governança das sociedades nos respectivos países membros, assim como proporcionar linhas de orientação para atores como bolsas de valores,

17 O Instituto Brasileiro de Governança Corporativa, fundado em novembro de 1995 (na época, como Instituto Brasileiro de Conselheiros de Administração (IBCA), é uma organização sem fins lucrativos dedicada à promoção da governança corporativa no Brasil, fomentador de práticas e discussôes sobre o tema.

18 A Organização para a Cooperação e o Desenvolvimento Econômico é um organismo composto por 34 países membros, que reúne países industrializados e também emergentes, com intuito de intercâmbio de informaçóes e alinhamento de políticas, com o objetivo de potencializar o crescimento econômico e assim colaborar com o desenvolvimento de todos os membros.A OCDE manifesta preocupação especial com o tema da governança, tendo inicialmente desenvolvido e publicado, em 1999, os Princípios da OCDE sobre o Governo das Sociedades, que em seguida foram revistos e republicados, em 2004. Registre-se que o Brasil não é membro da OCDE, mas junto com China, Índia, Indonésia e Africa do Sul é considerado parceiro-chave.

19 Optou-se pela referência fiel ao termo governo das sociedades, utilizado no âmbito da OCDE. 
investidores, empresas e outras partes relacionadas ao tema das boas práticas de governo societário.

Todos os seis (6) princípios se encontram estruturados em torno da ideia geral de enquadramento do governo das sociedades. De com o primeiro princípio - assegurar a base para um enquadramento eficaz do governo das sociedades -, deve-se promover mercados transparentes e eficientes, em conformidade com o princípio do primado do direito, com articulação clara da divisão de responsabilidades entre diferentes autoridades encarregadas pela regulação e aplicaçáo das leis. O segundo princípio - os direitos dos acionistas e funçôes fundamentais do seu exercício - deve proteger e facilitar o exercício dos direitos dos accionistas. O terceiro princípio - o tratamento equitativo dos acionistas - deve assegurar tratamento equitativo de todos os acionistas, incluindo os minoritários e estrangeiros, os quais devem ter a oportunidade de obter reparação efetiva por violaçáo dos seus direitos. O quarto princípio - o papel dos outros sujeitos com interesses relevantes no governo das sociedades -, deve acautelar direitos legalmente consagrados, ou também aqueles estabelecidos através de acordos mútuos, que contemplem outros sujeitos com interesses relevantes na empresa; deve encorajar uma cooperação ativa entre as sociedades e esses sujeitos, seja na criação de riqueza e de emprego, como também na manutenção sustentada de empresas financeiramente saudáveis. O quinto princípio - divulgação de informação e transparência -, deve assegurar a divulgação prévia e objetiva de todas as informaçôes relevantes relativas à sociedade, especialmente quanto à situação financeira, desempenho, participaçóes sociais e governo da empresa. Por fim, o sexto e último princípio - as responsabilidades do órgão de administração -, deve assegurar a gestão estratégica da empresa, que contemple e permita acompanhamento e fiscalização eficazes da gestão pelo órgão de administração, com a consequente responsabilização perante a empresa e os seus acionistas.

Verifica-se que, dentre os princípios acima - que corporificam iniciativa cuja adesão é voluntária por parte das empresas, consitutindo assim mecanismo de soft law ${ }^{20}$, sem vinculação jurídica - há a preocupação com a temática dos conflitos internos, mas também referências expressas a questóes como a transparência, responsabilidade e contemplação de outros sujeitos com interesses relevantes na empresa.

\section{Pacto Global da Organização das Nações Unidas}

No âmbito das Nações Unidas, estabeleceu-se o Pacto Global da Organização das Naçôes Unidas (ONU), iniciativa em torno da ideia de alinhamento das operaçóes e estratégias das empresas a princípios universalmente aceitos em quatro grandes áreas: direitos humanos, trabalho, meio ambiente e combate à corrupção ${ }^{21}$.

20 Soft law indica direito brando, flexível; por sua vez, hard law consiste num direito prescritivo, cogente. As diferenças mais marcantes sobre os termos serão tratadas no item 7 do trabalho.

21 Disponível em: <http://www.unglobalcompact.org>. Acesso em: 10 mai. 2015. 
O Pacto objetiva constituir-se como uma estrutura capaz de promover e auxiliar no desenvolvimento, implementação e divulgação de políticas e práticas de sustentabilidade, auxiliando assim o aperfeiçoamento dos modelos de gestão empresariais, através do seu alinhamento à temática da sustentabilidade.

Foram eleitos dez diferentes princípios, sendo dois na área de direitos humanos, quatro relativos a questôes ligadas ao trabalho, três relacionados ao meio ambiente e um princípio de combate à corrupção ${ }^{22}$. Tais princípios são baseados na Declaração Universal dos Direitos Humanos, na Declaração da Organização Internacional do Trabalho (OIT) sobre Princípios e Direitos Fundamentais no Trabalho, na Declaração do Rio sobre Meio Ambiente e Desenvolvimento e na Convenção das Naçóes Unidas Contra a Corrupção.

O Pacto congrega iniciativas interessantes no que diz respeito à assunção de "compromissos" 23 de implementação, divulgação e promoção dos princípios, constituindo incentivo para a integração dos mesmos à estratégia e à cultura organizacional das empresas, aos processos de tomada de decisóes, a tomada de medidas de apoio às questóes e objetivos mais amplos da ONU, a divulgação pública de informes ou relatórios contendo descrição de como vêm sendo adotados os princípios, assim como a divulgação e defesa da causa do Pacto Global em favor de práticas empresariais mais responsáveis.

É oportuno frisar que, tal como em relação aos Princípios da OCDE, o Pacto Global se trata de uma iniciativa cuja adesão é voluntária por parte das empresas, consistindo também um mecanismo de soft law, sem vinculação jurídica.

\section{Os Impactos da Sustentabilidade e da Noção de Valor Compartilhado no Governo da Empresa}

Particularmente nas últimas duas décadas, o tema da sustentabilidade passou a integrar a pauta de discussóes sobre as empresas e o seu governo ${ }^{24}$.

22 Princípios: 1) As empresas devem apoiar e respeitar a proteção dos direitos humanos reconhecidos internacionalmente; 2) Certificar-se de que não são cúmplices em abusos de direitos humanos; 3) As empresas devem defender a liberdade de associação e o reconhecimento efetivo do direito à negociação coletiva; 4) A eliminação de todas as formas de trabalho forçado ou compulsório; 5) A erradicaçáo efetiva do trabalho infantil; 6) A eliminação na discriminação no emprego e ocupaçấo; 7) As empresas devem apoiar uma abordagem preventiva sobre os desafios ambientais; 8) Desenvolver iniciativas a fim de promover maior responsabilidade ambiental; 9) Incentivar o desenvolvimento e a difusão de tecnologias ambientalmente sustentáveis; 10) As empresas devem combater a corrupção em todas as suas formas, inclusive extorsão e propina.

23 Ver parágrafo seguinte, onde será explicitada a natureza não vinculativa destes compromissos.

24 Desse contexto de mudanças relacionadas às noçóes de acomodação de interesses particulares e compromissos sociais, emergem imperativos como a transparência, ou seja, "a ideia de que a empresa não apenas se compromete, mas também aceita prestar contas quanto à maneira pela qual honra seus compromissos" (LAVILLE, 2009, p. 27-28). Neste sentido, a demonstraçấo do comportamento da empresa perante o 
Como visto nos dois tópicos anteriores, o debate se insere no âmbito de preocupação de algumas importantes organizaçóes internacionais, como a OCDE e a ONU, e também em inúmeros países. Neste ponto, importante destacar que o documento final da Conferência das Naçóes Unidas sobre Desenvolvimento Sustentável, em seu parágrafo 13, reconhece participação central da iniciativa privada e das empresas no desenvolvimento sustentável, que "solo se puede lograr forjando una alianza amplia entre las personas, los gobiernos, la sociedad civil y el sector privado, trabajando juntos a fin de lograr el futuro que queremos para las generaciones presentes y futuras". ${ }^{25}$ De acordo com esta concepção, a empresa é entendida como um ator social indispensável à realização do desenvolvimento com sustentabilidade.

De fato, a coerência e compatibilidade entre discurso e práticas empresariais devem encontrar no governo da empresa um efetivo instrumento. Trata-se de um importante mecanismo para alinhar a gestão empresarial aos imperativos da sustentabilidade e às

seu conjunto de públicos e toda a sociedade engloba a discussão sobre a necessidade de divulgação pública de relatórios que evidenciem suas performances sociais e ambientais, assim como do impacto de suas atividades e eventuais medidas de prevenção. Em outras palavras, os seus informes ou relatórios sobre sustentabilidade, documentos demonstrativos de um conjunto de práticas empresariais, que divulgam publicamente o desempenho econômico, ambiental e social do relator. Em nível mundial, a "Global Reporting Initiative” (GRI) é uma organização internacional que promove uma série de diretrizes e parâmetros para a elaboração de relatórios sobre sustentabilidade, estabelecendo princípios e indicadores para a medição e comunicaçáo do comportamento e desempenho das organizaçóes. Atualmente, a estrutura da GRI é utilizada por organizaçōes do mundo inteiro como referencial para a elaboração dos informes sobre sustentabilidade. Quanto ao conteúdo dos relatórios, são evidenciados, além do desempenho econômico, ambiental e social, questôes como práticas trabalhistas e trabalho decente, direitos humanos, sociedade (enfocam os impactos que as organizaçôes geram nas comunidades em que atuam e como os riscos de sua interaçấo com outras instituiçôes são geridos e mediados) e responsabilidade pelo produto. Disponível em: <http://www.globalreporting.org/resourcelibrary/Brazil-Portuguese-G3-Reporting-Guidelines.pdf>. Acesso em: 23 mar. 2015. No Brasil, não há uma obrigação legal no sentido da divulgação de informes ou relatórios sobre sustentabilidade. Embora exista uma recomendação da BMFBOVESPA - instituição administradora do mercado de valores mobiliários brasileiro, estimulando a publicação, tal documento se caracteriza eminentemente como direito não prescritivo, ou seja, recomendação proveniente de mecanismos de soft law, também conhecidos como soft norm ou droit doux. Deve-se ressaltar que tais recomendaçóes náo constituem norma jurídica, ou seja, os referidos textos não estabelecem obrigaçôes de direito positivo e seus dispositivos não são cogentes. Na Europa, uma diretiva do Parlamento Europeu e do Conselho, número de referência COM (2013) 207, engloba uma proposta no sentido de obrigar grandes empresas a divulgarem informaçóes não financeiras relevantes. A partir de duas resoluçôes do Parlamento Europeu, intituladas "Responsabilidade social das empresas: comportamento responsável e transparente das empresas e crescimento sustentável" e "Responsabilidade social das empresas: promoção dos interesses da sociedade e via para uma retoma sustentável e inclusiva”, reconheceu-se a necessidade de melhorar a transparência da informação social e ambiental, elemento considerado indispensável para a responsabilidade social das empresas. Deve-se registrar, contudo, que a proposta ainda se encontra em tramitação, não constituindo obrigação legal. Disponível em: http:// www.europarl.europa.eu/registre/docs_autres_institutions/commission_europeenne/com/2013/0207/ COM_COM(2013)0207_PT.pdf>. Acesso em: 15 mai. 2015.

25 ORGANIZAÇÃO DAS NAÇÓES UNIDADAS. Conferência das Nações Unidas sobre desenvolvimento Sustentável. Parágrafo 13. Disponível em: <http://www.daccess-dds-ny.un.org/doc/UNDOC/ GEN/N11/476/13/PDF/N1147613.pdf?OpenElement>. Acesso em: 12 jan. 2015. 
ideias em torna da noção de valor compartilhado. Por outro lado, muitas empresas, especialmente quando da divulgação de missão, visão e valores, têm se autoproclamado "sustentáveis" - o mesmo na divulgação pública de seus relatórios sobre sustentabilidade -, mas na prática engendram uma série de açóes diametralmente opostas aos imperativos da sustentabilidade e também da noção de criação de valor compartilhado ${ }^{26}$. Em que pese a necessidade de consolidação de um sistema capaz de acomodar atividade econômica, meio ambiente e bem estar da sociedade, a sustentabilidade e a noção de valor compartilhado, embora frequentemente presentes no discurso, parecem ainda pendentes de incorporação efetiva à prática do governo da empresa.

Os paradigmas da sustentabilidade e da noção de valor compartilhado devem impactar efetivamente no governo da empresa, no sentido do alinhamento de uma série de questóes como aquelas propostas no Princípios da OCDE e no Pacto Global, entre outras como: i) políticas de pessoal que respeitem os direitos dos colaboradores das empresas e que favoreçam o seu desenvolvimento enquanto seres humanos, através do oferecimento de condições dignas de trabalho e remuneração, possibilidades de progresso na carreira e programas de capacitação para treinamento contínuo; ii) arranjos internos que garantam aos acionistas, especialmente os minoritários, possibilidade de participação ativa nos rumos dos negócios, com instâncias diretivas que lutem para abolir/amenizar os eventuais conflitos de interesses; iii) jogo limpo e transparente com os consumidores de produtos e serviços, com oferta de produtos e serviços de boa qualidade e com preços razoáveis; iv) políticas de proteção ao meio ambiente e engajamento na agenda mundial diante deste campo, contribuindo a nível local, regional, nacional ou mesmo internacional.

A visão acima se encontra presente na doutrina de BENN e DUNPHY (2007), segundo os quais o estudo do tema do governo da empresa deve estar alinhado com suas ligaçóes com performance social e sustentabilidade. O mesmo se diga em relação a VAZ (2011, p. 19), para quem é necessário compreender que as principais questôes que se

26 Uma ação que, no âmbito brasileiro, pode ser apontada como contrária à ideia em questáo é a formulaçâo, por determinadas empresas, das chamadas "listas sujas" de empregados. Em alguns casos, reveladores de um agir dissociado da mesma, dados constantes de informações processuais sobre reclamaçóes trabalhistas ajuizadas são divulgados e levam outros empregadores a dispensar ou não admitir empregados que tenham recorrido ao Judiciário com demandas sobre eventuais direitos trabalhistas. Exemplo paradigmático foi o da Companhia Vale. Por ter criado uma "lista suja" com nomes e informaçóes sobre empregados que ajuizaram reclamaçôes trabalhistas contra ela, foi condenada ao pagamento de indenização por dano moral coletivo, no importante de $\mathrm{R} \$ 800.000,00$ (oitocentos mil reais), a serem revertidos ao Fundo de Amparo ao Trabalhador, após ação civil pública ajuizada pelo Ministério Público do Trabalho. A empresa foi condenada pela $12^{\text {a }}$ Vara do Trabalho de Vitória/ES, decisão que foi mantida pelo Tribunal local e também pela Quinta Turma do TST (Recurso de Revista no 103600-95.2006.5.17.0012). A reiterada prática das "listas sujas" levou o Conselho Superior da Justiça do Trabalho a editar a Resoluçáo $\mathrm{n}^{\circ}$ 139, de 24 de junho de 2014, que dispóe sobre medidas a serem adotadas pelos Tribunais Regionais do Trabalho com a finalidade de impedir ou dificultar a busca de nomes de empregados para a composição das referidas listas. 
colocam no domínio do governo da empresa dizem respeito, essencialmente, aos mecanismos de repartição desse poder, do controle e das responsabilidades internas, mas sem deixar de descuidar dos demais interesses de outras partes, os stakeholders, interesses estes que também gravitam em torno da empresa e devem ser harmonizados com os interesses dos titulares da atividade econômica e com os da própria empresa.

A incorporação de questóes como a sustentabilidade e a noção de valor compartilhado ao governo da empresa começa a ser objeto de preocupação de instituições administradoras de mercados de capitais, como no caso da brasileira BM\&FBOVESPA. Em 2011, foi publicado o Novo valor - sustentabilidade nas empresas: como começar, quem envolver e o que priorizar, em que são elencados 13 passos rumo à sustentabilidade: i) envolver a direção da empresa; ii) descobrir o que precisa ser mudado; iii) estabelecer prioridades; iv) assumir compromissos públicos; v) estabelecer a governança da sustentabilidade; vi) checar a identidade; vii) engajar os stakeholders; viii) elaborar uma política de sustentabilidade; ix) envolver o público interno; $x$ ) ajustar o sistema de gestáo; xi) definir e acompanhar indicadores; xii) estabelecer metas; xiii) relatar suas conquistas e desafios. Dentre as propostas, destaca-se a ideia de governança da sustentabilidade, no sentido da criação, pelas empresas, de uma estrutura de governança efetivamente voltada para a sustentabilidade. Neste sentido, a BM\&FBOVESPA sugere a criação de três tipos órgãos: i) Comitê Executivo de Sustentabilidade (formado por representantes do conselho de administração); ii) Comitê de Sustentabilidade (composto por diretores); e iii) Comissão de Sustentabilidade (reunindo superintendentes e gerentes).

Percebe-se, assim, que as temáticas da sustentabilidade e da criação de valor compartilhado devem definitivamente estar alinhadas aos demais escopos - solução de conflitos de agência entre titularidade/gestão e majoritários/minoritários, desempenho financeiro etc. -, para o qual os diversos modelos de governo da empresa procuram apresentar respostas.

\section{0 Papel do Direito na Questão do Governo da Empresa}

O tema do governo da empresa tem gerado discussóes entre a conveniência do estabelecimento de regramento prescritivo ou regras de governança, de adesão contratual. De acordo com SCHAPIRO (2010, p. 36-37), os conjuntos de dispositivos regulatórios "são conformados pelo ordenamento jurídico e assumem um caráter prescritivo, voltando-se a apresentar os contornos e conteúdos que devem balizar a relação entre o agente e o principal, no universo de uma corporaçáo." Por outro lado, as chamadas regras de governança "apresentam o status de um arranjo contratual entre os atores da firma e dedicam-se a estabelecer os termos por meio dos quais serão processadas as diversas relaçóes existentes entre a companhia e os seus stakeholders". 
Em nível mundial, tem prevalecido os instrumentos não prescritivos, como: i) Code of Conduct (Itália); ii) Código de Mejores Prácticas Corporativas (México); iii) Corporate Governance in the Netherlands (Holanda); iv) European Corporate Governance Institute; v) Korean Code of Best Practice for Corporate Governance; vi) Principios de Buen Gobierno del Peru; vii) Report on the Belgian Comission on Corporate Governance (Bélgica); viii) Swedish Corporate Governance Policy (Suíça); ix) The UK Corporate Governance Code (Reino Unido). Por outro lado, o Código de Governança Corporativa Alemão, instituído em 26-02-2002, embora baseado nos Princípios de Governança Corporativa da OCDE, graças ao previsto na Lei das Sociedades Anônimas alemã, art. 161, com a redação que lhe foi conferida pela Lei de Transparência e Publicidade, possui força cogente, não constituindo apenas um código de autorregulação, mas sim parte integrante do ordenamento jurídico alemão (ALBUQUERQUE, p. 30-38).

Não obstante ao aumento de adesôes volunatárias a modelos que se fundamentam nas recomendaçôes (sob a forma de princípios gerais) veiculadas pela OCDE e no Pacto Global, a ausência de coercibilidade estatal mantém uma flexibilidade ao conteúdo normativo de tais dispositivos, tornando mais incerto o alcançar da efetiva incorporação, ao governo da empresa, de temas relacionados à sustentabilidade e à criaçáo de valor compartilhado. Deve-se ressaltar que tais recomendaçóes não constituem norma jurídica, os referidos textos não estabelecem obrigaçóes de direito positivo e, portanto, não são cogentes.

Conforme destaca CHEVALLIER (2009, p.166-169), estes instrumentos "indicam os 'objetivos' que seria desejável atingir, fixam 'diretivas' que seria oportuno de seguir, formulam 'recomendaçóes que seria bom de respeitar", com a sua aplicação dependendo não do elemento da coercibilidade mas sim da adesão voluntária dos destinatários, consistindo assim num "direito brando" - soft law -, que póe em segundo plano a noção de comando e assim representa concepção mais flexível da normatividade jurídica. Ao que parece, esta não é a melhor e mais indicada opção para o tratamento normativo da questão.

No Brasil, pela ausência de força cogente, os arranjos éticos e contratuais (mecanismos de soft Law) associados ao tema do governo das empresas têm se revelado insuficientes para tutelar a sustentabilidade e a necessária harmonização dos interesses entre os conjuntos de stakeholders ${ }^{27}$. Algumas dessas falhas podem ser identificadas na análise das

27 No Brasil, a BMFBOVESPA, na condição de instituição administradora do mercado de capitais, exerce uma série de funçôes dentre as quais a autorreguladora. No exercício desta função, foram criados os chamados segmentos de listagem de governança corporativa. Atualmente, os segmentos são: BOVESPA MAIS, BOVESPA MAIS NÍVEL 2, NOVO MERCADO, NÍVEL 2, NÍVEL 1 e TRADICIONAL. Cada um reúne um conjunto diferenciado de exigências que, cumpridas, permitem às companhias a listagem respectiva. As regras se restringem às sociedades anônimas de capital aberto listadas na BMFBOVESPA, ou seja, aquelas companhias com valores mobiliários negociados no mercado de capitais, ou também aquelas que se encontram numa fase de transiçáo e pretendem realizar a abertura de capital. Mesmo no 
conclusôes de interessante estudo empírico realizado por BLACK, CARVALHO e GORGA (2009). Os autores avaliaram o panorama das práticas de governança corporativa no Brasil, a partir da análise de 88 (oitenta e oito) companhias com controle privado nacional. Dentre as suas conclusóes, merecem destaque: i) os conselhos de administração da maioria das empresas privadas brasileiras são compostos totalmente ou quase totalmente por membros ou representantes da família ou grupo controlador; ii) muitas empresas não têm nenhum conselheiro independente; iii) divulgaçóes de informaçôes financeiras estão aquém dos padrốes internacionais; iv) muitas empresas fornecem suas demonstraçóes financeiras em inglês em seu website; v) uma pequena parte fornece direitos de proteção para os acionistas minoritários em uma venda de controle da empresa.

nível mais alto de governança, o NOVO MERCADO, as regras se encontram direcionadas mais para a solução dos conflitos entre titularidade/gestão e majoritários/minortitários, sem aprofundamento no que diz respeito ao reconhecimento de interesses de outras partes externas à companhia, mais precisamente nas relações com os stakeholders. Além do nível tradicional, o sistema contempla ainda outros 5 (cinco) níveis diferenciados, cabendo a cada empresa listada optar por um deles, desde que promova as adaptaçóes necessárias ao seu estatuto social. As regras estipuladas se caracterizam eminentemente como direito nâo prescritivo, na medida em que a adesão a elas é voluntária e contratual. Constituem, assim, mecanismos de soft law, também conhecidos como soft norm ou droit doux. Como exemplos de mecanismos náo cogentes de governança corporativa podem ser citados, entre outros: i) o Código das Melhores Práticas de Governança Corporativa, editado originalmente em 1999, pelo Instituto Brasileiro de Governança Corporativa, e revisado em 2001, 2004 e 2009, sua versão atual; ii) a Cartilha de Recomendaçóes da CVM sobre Governança Corporativa, de junho de 2002; iii) o Código Previ de Melhores Práticas sobre Governança Corporativa; iv) Orientação do CODIM - Comitê de Orientação para Divulgação de Informaçóes ao Mercado - no 13/2012, que recomenda a adoção de boas práticas de divulgação de informaçóes, prestação de contas e governança corporativa; v) Código Abrasca (Associação Brasileira das Companhias Abertas) de Autorregulação e Boas Práticas das Companhias Abertas. O Instituto Brasileiro de Governança Corporativa (IBGC), fomentador de práticas e discussóes sobre o tema, tem editado os chamados Códigos de Melhores Práticas de Governança Corporativa. O primeiro Código, de 1999, teve como foco a atuação dos conselhos de administração. A edição seguinte, de 2001, foi marcada pela ampliação das recomendaçôes para os demais agentes da governança, como sócios, gestores, auditorias e conselhos fiscais. Em 2004, foram feitas pequenas alteraçôes de conteúdo, pouco significativas. A versão atual, de 2009, teve como proposta a criação de um ambiente organizacional/institucional mais sólido, justo, responsável e transparente. Há em curso um projeto de revisão do conteúdo atual, tendo sido realizada, no dia 12-052015, uma audiência restrita (com a participação associados, membros de comissóes e representantes de instituiçóes parceiras), com a finalidade de discussão e formulação de propostas. Por fim, deve-se frisar que os Códigos não constituem norma jurídica, caracterizando-se como instrumentos de soft law. Alguns dispositivos da Lei 6.404/76, que dispóe sobre as sociedades por açóes, de certa meneira relacionam o tema do governo da empresa com a noção de stakeholders, assumindo um caráter prescritivo. $\mathrm{O}$ artigo 116 da Lei no 6.404/76, em seu parágrafo único, referencia o dever do administrador em fazer a companhia realizar o seu objeto e cumprir a sua função social, com responsabilidades perante os demais acionistas, os colaboradores (empregados) e a comunidade como um todo. Por seu turno, o artigo 154 da mesma Lei dispôe que "o administrador deve exercer as atribuiçôes que a lei e o estatuto lhe conferem para lograr os fins e no interesse da companhia, satisfazer as exigências do bem público e da função social da empresa.” E, em seu $₫ 4^{\circ}$, “o conselho de administraçáo ou a diretoria pode autorizar a prática de atos gratuitos razoáveis em benefício dos empregados ou da comunidade de que participe a empresa, tendo em vista suas responsabilidades sociais." São, todos, dispositivos abertos que dificultam a implementação prática das ideias. O que significa, do ponto de vista da gestão, por exemplo, responsabilidades perante colaboradores e comunidade como um todo? 
A existência de conflitos internos de agência, falhas na apresentação de informaçóes financeiras ao mercado, diminuta participação de conselheiros independentes, falta de representação dos empregados nos conselhos de administração, não incorporação da política de divulgação de informações sobre sustentabilidade etc., são apenas alguns exemplos de situaçóes que demandam reflexão sobere o regramento prescritivo como meio regulatório mais adequado ao tratamento de determinadas matérias.

Defende-se que as novas perspectivas e exigências em torno da adequação do agir empresarial à sustentabilidade e à ideia de valor compartilhado impóem uma participação mais efetiva do direito - de um direito prescritivo e não de um direito brando, flexível - no sentido da criação e integração, aos ordenamentos jurídicos, de conteúdos legais prescritivos alinhados ao desenho de um futuro que se espera melhor, para o qual as empresas sáo parte tanto do caminho quanto do resultado final.

De fato, a aposta é no papel transformador do direito, e também das empresas, para a harmonização de interesses particulares dos titulares do exercício da atividade econômica com compromissos sociais atrelados à sustentabilidade e à ideia de valor compartilhado. Esta concepção do direito, mais prescritivo, menos flexível ou brando, aposta na premissa de que determinadas questôes, como a divulgação públicas das performances econômicas, sociais e ambientais das empresas, por sua importância, devem ser observadas mais do ponto de vista daquilo que é correto fazer - e, consequentemente, de se exigir coercitivamente -, e menos sob o enfoque dos custos para a sua realização.

O desafio permanecerá sendo, nas escolhas normativas, a eleição daqueles interesses mais relevantes, indispensáveis, mais aptos a consagrar as noçóes de sustentabilidade e valor compartilhado, e os efeitos socialmente positivos decorrentes de sua aplicação. Tais interesses merecem ser alçados de meras recomendaçóes à condição de deveres jurídicos.

\section{Conclusões}

Com a presente pesquisa, foi possível reconhecer a sustentabilidade como elemento estruturante do Estado Constitucional, um novo paradigma do direito indutor de pautas axiológicas em diversos níveis. Tal fenômeno, de múltiplas faces, conduz à necessidade de melhora e ajuste contínuos das práticas dos diversos atores sociais, públicos e privados. Deve repercutir, também, na ação da empresa, entendida não como mera expressão de uma atividade econômica, mas sim como ator social diretamente vinculado à responsabilidade de acomodação de interesses particulares com compromissos sociais.

A sustentabilidade empresarial se encontra associada à ideia de criação e preservação de valor compartilhado a um conjunto de partes interessadas, no curto, médio e longo prazos, o que envolve aspectos econômicos, ambientais e sociais. Neste sentido, algumas 
questóes assumem a condição de imperativos e impactam diretamente no tema do governo da empresa (ex.: divulgação pública de suas performances econômicas, sociais e ambientais, por intermédio dos chamados relatórios sobre sustentabilidade), o que engloba a necessidade de alinhamento das práticas empresariais às ideias em torno da sustentabilidade e também da noção de criação de valor compartilhado a um conjunto de partes interessadas, para além dos titulares da atividade econômica.

Na doutrina, a governança tem sido apresentada primordialmente como um conjunto de medidas voltadas à solução de problemas de agência entre titularidade e gestão, ou também entre titulares majoritários e minoritários do capital social. No plano internacional, organismos como a OCDE e a ONU já consagram algumas diretrizes de princípios de governo de empresa associados às ideias de sustentabilidade e criação de valor compartilhado, mas tais mecanismos são de adesão voluntária, constituindo soft law, direito não prescritivo.

Conclui-se que a visão tradicional da doutrina é insuficiente para uma efetiva adequação do governo da empresa à sustentabilidade e também para a harmonização dos múltiplos interesses, privados e públicos, que gravitam em torno da empresa. Quanto às diretrizes de princípios de governo de empresa no âmbito da OCDE e da ONU, embora em alguns sentidos indiquem associação às ideias de sustentabilidade e criação de valor compartilhado, constituem direito não prescritivo e não implicam vinculação jurídica por parte das empresas. $\mathrm{O}$ mesmo se diga em relação aos códigos de conduta e boas práticas, que proliferam a nível mundial, normalmente fundamentados em tais princípios gerais.

Todas as questóes explicitadas indicam a necessidade de tratamento normativo da questão no sentido da criação e integração, aos ordenamentos jurídicos, de obrigaçóes legais associadas aos temas, com o cuidado de, nas escolhas normativas, promover-se a eleição daqueles interesses mais relevantes, indispensáveis, mais aptos a consagrar as noções de sustentabilidade e valor compratilhado, e os efeitos socialmente positivos decorrentes de sua aplicação. Transformar recomendações em obrigação legal constante de lei formal estatal, prescrição a qual os destinatários serão obrigados a obedecer, atribui uma certeza maior quanto ao enquadramento normativo das empresas a diretrizes e princípios táo relevantes.

\section{Referências}

ABRAMOVAY, Ricardo. Muito além da economia verde. São Paulo: Abril, 2012.

ALBUQUERQUE, Roberto de Araújo Chacon de. A proteção ao investidor no Código de Governança Corporativa Alemão. Rev. Direito GV, v. 4, n. 1, p. 29-48, jan./jun. 2008. Disponível em: <http://www.scielo.br/pdf/rdgv/v4n1/a03v4n1.pdf>. Acesso em: 10 mai. 2015. 
ANDRÉS, Elena Esteva de; PIMENTEL, Duarte. Empresa e reproducción social ampliada: los contributos del análisis societal. Sociologia, Problemas e Práticas, Lisboa, n. 47, p. 35-45, 2005.

ARNOLDI, Paulo Roberto Colombo; MICHELAN, Taís Cristina de Camargo. Novos enfoques da função social da empresa numa economia globalizada. Revista de Direito Mercantil, Industrial, Econômico e Financeiro, São Paulo, ano XXXIX (Nova Série), jan./mar., p. 157-162, 2000.

ATKINSON, Anthony; WATHERHOUSE, John A. A stakeholders approach to strategic performance measurement. Sloan Management Review, Massachussets, v. 38, n. 3, p. 25-36, set. 1997.

BENN, Suzane; DUNPHY, Dexter. Corporate Governance and Sustainability: Chalenges for Theory and Practice. New York: Routledge, 2007.

BERLE, Adolf.; MEANS, Gardiner. The Modern Corporation and Private Property. Nova Iorque: Macmillan, 1932.

BLACK, Bernard S.; CARVALHO, Antonio Gledson de; GORGA, Érica. The Corporate Governance of Privately Controlled Brazilian Firms. Revista Brasileira de Finanças, v. 7, 2009. Disponível em: <http://www.papers.ssrn.com/sol3/papers.cfm?abstract_ $\mathrm{id}=1003059>$. Acesso em: 15 mai. 2015.

BM\&FBOVESPA. Novo valor - sustentabilidade nas empresas: como começar, quem envolver e o que priorizar. São Paulo: BM\&FBOVESPA, 2011.

CANOTILHO, José Joaquim Gomes. O Princípio da sustentabilidade como Princípio estruturante do Direito Constitucional. Revista de Estudos Politécnicos, v. VIII, n. 13, 2010 .

CHAVES, Vinicius Figueiredo; FLORES, Nilton Cesar. Empresa sustentável: um estudo sobre os atuais caminhos da divulgação pública de informes sobre sustentabilidade no Brasil. Revista Juris Poiesis, Rio de Janeiro, ano 17, n. 17, p. 181-200, jan.-dez. 2014 .

CHEVALliER, Jacques. O Estado Pós-Moderno (Coleção Brasil-França de Direito Público) Belo Horizonte: Fórum, 2009.

CRUZ, Paulo Márcio; BODNAR, Zenildo. O novo paradigma do direito na pós-modernidade. Revista de Estudos Constitucionais, Hermenêutica e Teoria do Direito (RECHTD), v. 3, n. 1, p. 75-83, jan.-jun. 2011. Disponível em: <http://www. http:// revistas.unisinos.br/index.php/RECHTD/article/view/777/1761> . Acesso em: 05 abr. 2015 .

FEITOSA, Maria Luiza Pereira de Alencar Mayer. Desenvolvimento econômico e direitos humanos. Boletim de Ciências Económicas, Coimbra, LII, 2009, p. 33-34. Disponível em: <http://www.uc.pt/fduc/publicacoes/bce/2009>. Acesso em: 02 jun. 2014. 
FERRER, Gabriel Real; GLASENAPP, Maikon Cristiano; CRUZ, Paulo Márcio. Sustentabilidade: um novo paradigma para o direito. Revista Novos Estudos Jurídicos Eletrônica, v. 19, n. 4, edição especial, p. 1433-1464, 2014.

FLORES, Nilton César da Silva (org.). A Sustentabilidade Ambiental em suas Múltiplas Faces. São Paulo, Millennium, 2012.

FREEMAN, Edward R. Strategic Management: A Stakeholder Approach. Cambridge: Cambridge University Press, 2010.

FREEMAN, Edward R.; REED, David L. Stockholders and Stakeholders: A New Perspective on Corporate Governance. California Management Review, vol. XXV, n. 03, p. 88-106, 1983.

GLOBAL REPORTING INITIATIVE. [on line]. Disponível em: <//www.globalreporting.org/languages/Portuguesebrazil/Pages/default.aspx>. Acesso em: 23 jul. 2014.

INSTITUTO BRASILEIRO DE GOVERNANÇA CORPORATIVA (IBGC). Código das Melhores Práticas de Governança Corporativa. $4^{\mathrm{a}}$ ed. São Paulo: IBGC, 2009.

JENSEN, Michael C.; MECKLING, William H. Theory of the firm: managerial behavior, agency costs and ownership structure. Journal of Financial Economics, v. 3, n. 4, oct. 1976.

LACERDA, Emanuela Cristina A.; Rosa, Alexandre Morais da; FERRER, Gabriel Real. A Propriedade ante o Novo Paradigma do Estado Constitucional Moderno: A Sustentabilidade. Revista Novos Estudos Jurídicos - Eletrônica, v. 19, n. 4, edição especial, p. 1185-1219, 2014.

LAVILLE, Élisabeth. A empresa verde. São Paulo: Ote, 2009.

LEMOS JÚNIOR, Eloy Pereira. Empresa \& Função Social. Curitiba: Juruá, 2009.

MACKEY, John; SISODIA, Raj. Capitalismo Consciente. São Paulo: HSM, 2013.

MAHONEY, William F. Manual do RI: Princípios e Melhores Práticas de Relaçóes com Investidores. Rio de Janeiro: IMF, 2007.

MARIANO, Leila. O Poder Judiciário e a Sustentabilidade. In: FLORES, Nilton César da Silva (org.). A Sustentabilidade Ambiental em suas Múltiplas Faces. São Paulo, Millennium, 2012.

MEADOWS, D. H. et al. The limits to growth. New York: Universe Books, 1972.

MONTIBELLER FILHO, Gilberto. Ecodesenvolvimento e Desenvolvimento Sustentável - Conceitos e Princípios. Textos de Economia, Florianópolis, v. 4, n. 1, p. 131$142,1993$.

NASCIMENTO, Elimar Pinheiro do. Trajetória da sustentabilidade: do ambiental ao social, do social ao econômico. Estudos Avançados, v. 26, n. 74, p. 51-64, 2012. 
ORGANIZAÇÃO DAS NAÇÓES UNIDAS - ONU. Conferência das Naçóes Unidas sobre desenvolvimento Sustentável. Parágrafo 13. Disponível em: <http://www.daccess-dds-ny.un.org/doc/UNDOC/GEN/N11/476/13/PDF/N1147613.pdf?OpenElement>. Acesso em: 12 jan. 2015.

ORGANIZAÇÃO DAS NAÇÕES UNIDAS - ONU. Pacto Global das Nações Unidas. Disponível em: <http://www.unglobalcompact.org>. Acesso em: 10 mai. 2015.

ORGANIZAÇÃO PARA A COOPERAÇÃO E DESENVOLVIMENTO ECONÔMICO - OCDE. Principios da OCDE sobre o Governo das Sociedades. OCDE, 2004. Disponível em: <http://www.oecd.org/daf/ca/corporategovernanceprinciples/33931148.pdf>. Acesso em: 06 abr. 2015.

PARLAMENTO EUROPEU. Disponível em: http://www.europarl.europa.eu/registre/docs_autres_institutions/commission_europeenne/com/2013/0207/COM_ COM(2013)0207_PT.pdf>. Acesso em: 15 mar. 2015.

PINHEIRO, Silvia Marina. O Desenvolvimento Sustentável e as Empresas. In: OLIVEIRA, Carina Costa de; SAMPAIO, Rômulo Silveira da Rocha (orgs.). A Economia Verde no Contexto do Desenvolvimento Sustentável - a governança dos atores públicos e privados. Rio de Janeiro: FGV, 2011.

PORTER, Michael E.; KRAMER, Mark R. The big idea: Creating Shared Value - how to reinvent capitalism and unleash a wave of innovation and growth. Harvard Business Review. Jan./fev. 2011.

SACHS, Ignacy. Estratégias de Transição para o Século XXI - Desenvolvimento e Meio Ambiente. São Paulo, Studio Nobel - Fundap, 1993.

SCHAPIRO, Mario Gomes. Novos parâmetros para a intervenção do Estado na economia. São Paulo: Saraiva, 2010.

SEN, Amartya; KLIKSBERG, Bernardo. As pessoas em primeiro lugar: a ética do desenvolvimento e os problemas do mundo globalizado. São Paulo: Companhia das Letras, 2010.

SEVERINO, Antônio Joaquim. Metodologia do Trabalho Científico. 23a ed. São Paulo: Cortez, 2007.

SILVA, Fernando. Códigos de Governo Societário: Does one size fit all? Caderno do Mercado de Valores Mobiliários, n. 33, p. 40-71, ago. 2009. Disponível em: <http://www. cmvm.pt/CMVM/Publicacoes/Cadernos/Documents/CadernosMVM33Final1. pdf>. Acesso em: 07 abr. 2015.

STOUT, Linn. The Shareholder Value Myth. San Francisco: Berrett-Koehler, 2012.

TEIXEIRA, Ana Bárbara Costa. A empresa-instituição. São Paulo, 2010, 272f. Dissertação (Mestrado em Direito). Pós-Graduação em Direito da Faculdade de Direito da Universidade de São Paulo. 
TOMASEVICIUS FILHO, Eduardo. A função social da empresa. Revista dos Tribunais, São Paulo, ano 92, v. 810, abr. 2003.

VAZ, João Cunha. A Regra de Não Frustração da OPA e a Aquisição do Controlo. Coimbra, 2011, 398 fls. Tese (doutorado em ciências jurídico-empresariais). Pós-graduaçáo em Direito da Faculdade de Direito da Universidade de Coimbra.

WALD, Arnoldo. O governo das empresas. Revista de Direito Bancário, do Mercado de Capitais e da Arbotragem, São Paulo, ano 5, n. 15, p. 53-78, jan.-mar. 2002. 